\title{
KONSEP MODEL PENGEMBANGAN IDEA MANAGEMENT WORLD VISION INDONESIA
}

\author{
Hendra \\ Information Systems Department, School of Information Systems, Binus University \\ Jl. K.H. Syahdan No. 9, Palmerah, Jakarta Barat 11480 \\ hendra@mylearningplus.org
}

\begin{abstract}
The purpose of this article is to compose a development model that can be used to manage the process of idea conversion, structure idea from tacit to be explicit, determine priority scale of an idea, accomodate idea discussion in a creative thinking, justify idea alignment with organization choices, and measure the impact of an idea management. The development model is shaped based on supported concept and tool of knowledge conversion, knowledge management cycle and its procedure, QCDSM objectives, organization alignment model, importance-urgency priority scale and six hats creative thinking. The result of this research is an integrated model with some designs of idea identification form and main functions of idea management application that are ready to be implemented.
\end{abstract}

Keywords: idea management, knowledge management, QCDSM

\begin{abstract}
ABSTRAK
Tujuan dari tulisan ini adalah menyusun suatu model pengembangan untuk mengelola perubahan ide, menstrukturkan ide dari tacit menjadi eksplisit, menentukan skala prioritas dari sebuah ide, mengakomodasi diskusi ide dalam sebuah pemikiran kreatif, menentukan keselarasan ide dengan pilihan organisasi, dan mengukur dampaknya. Model pengembangan yang ditujukan ini dibentuk dari konsep dan perangkat konversi pengetahuan, siklus dan prosedur pengelolaan pengetahuan, obyektif QCDSM, model keselarasan organisasi, skala prioritas, dan penggunaan six hats creative thinking. Hasil dari pekerjaan ini adalah suatu model pengembangan terintegrasi disertai dengan desain atribut identifikasi ide dan fungsi-fungsi utama dari sebuah aplikasi manajemen ide yang dapat siap diimplementasikan.
\end{abstract}

Kata kunci: manajemen ide, manajemen pengetahuan, QCDSM 


\section{PENDAHULUAN}

Idea Management (IM) merupakan salah satu topik knowledge management (KM) yang ditujukan untuk menghasilkan ide perbaikan secara terus menerus (continuous improvement) bagi operasional bisnis organisasi. Beberapa laporan dari organisasi yang mengaplikasikan idea management menunjukkan manfaat yang mendorong kinerja organisasi secara signifikan (Deichmann, 2012:15), seperti perusahaan telekomunikasi Jerman Deutshce Telekom yang mengimplementasikan 10.000 ide di tahun 2011 dan mengklaim dapat menghemat biaya sampai 136 juta Euro. Siemens juga melaporkan bahwa mereka telah mengimplementasikan 1,5 juta saran dari stafnya selama 100 tahun dan dari hal ini mereka dapat menghemat 3 triliun Euro, serta Shell yang telah mempatenkan 90 seri hak cipta yang berasal dari ide stafnya dari tahun 1996 hingga 2007

Melihat potensi manfaat dari IM ini, World Vision Indonesia (WVIDN) sebagai organisasi nirlaba kemanusian yang melakukan pengembangan masyarakat dengan fokus kepada anak-anak secara holistik, melakukan terobosan untuk meningkatkan kemampuan pembelajaran organisasinya. Kondisi saat ini terdapat tiga sektor pengembangan yang memiliki kompleksitas yang tingi yang dicakup dalam pengembangannya yaitu: ekonomi, pendidikan, dan kesehatan. Sampai saat ini terdapat 58 proyek pengembangan daerah yang meliputi hampir dua juta masyarakat layanannya. Melihat kondisi ini, salah satu karakteristik proses kerja dari organisasi kemanusiaan ini yang tampak adalah banyaknya proses pembelajaran dan ide-ide operasional yang bermunculan dan perlu untuk dikelola sehingga dapat mengikuti dinamika masyarakat layanan yang terjadi dengan beragam variasi permasalahan yang tersebar di berbagai daerah layanan dari Sabang sampai Merauke. Proses pembelajaran ini menjadi sangat penting karena organisasi perlu untuk dapat cepat menangkap ide-ide pengembangan dan kreativitas yang dimiliki oleh seorang staf di satu daerah untuk dapat dikelola dan direplikasi menjadi potensi inisiatif implementasi pengembangan secara nyata untuk skala yang lebih luas.

Beberapa hal yang menjadi permasalahan yang dialami WVIDN yang sekaligus diangkat menjadi topik permasalahan dalam tulisan ini dalam mengelola ide adalah sebagai berikut: (1) bagaimana organisasi dapat mengelola perubahan ide (idea conversion) yang berasal dari staf (tacit knowledge) hingga dapat disimpan (explicit knowledge), dipelajari, dipergunakan serta diukur dampaknya; (2) proses apa saja yang harus dilakukan sehingga dapat menjadi alur proses formal pengelolaan ide di WVIDN; (3) bagaimana menstrukturkan ide yang disampaikan oleh staf dengan cara yang standar sehingga organisasi/pihak lain dapat memberikan penilaian dengan sistematis; (4) bagaimana menentukan nilai prioritas sebuah ide dibandingkan dengan ide lainnya; (5) bagaimana mengakomodasi diskusi sebuah ide dalam suatu kelompok secara kreatif. Dalam hal ini sebuah ide yang disampaikan seseorang dapat didiskusikan tidak saja secara logis semata tetapi juga dapat dilakukan secara lateral/kreatif; (6) bagaimana WVIDN dapat menilai apakah sebuah ide selaras (align) dengan prinsip-prinsip, pilihan strategi, serta kapasitas organisasi; (7) indikator apa yang dapat diapakai untuk mengukur dampak dari sebuaih de dan idea management

Secara khusus bagi WVIDN, implikasi kerugian/ masalah bagi organisasi yang terdentifikasi apabila ide-ide dan hasil pembelajarannya dari para staf tidak terkelola dengan baik adalah sebagai berikut: (1) kerugian atas hilangnya potensi perbaikan bagi organisasi karena tidak terkelolanya hasil pembelajaran atas ide-ide baru yang timbul dari staf. Hal ini mengarah kepada hilangnya potensi aset pengetahuan organisasi (knowledge base) yang dapat dipergunakan sebagai dasar pembelajaran dan pertumbuhan organisasi (learning and growth). Pengukuran nilai kerugian (atau manfaat) atas keberadaan pengelolaan aset pengetahuan ini dilakukan menggunakan audit manajemen pengetahuan; (2) terjadinya pengulangan kesalahan atas hal yang sudah diselesaikan atau usaha kerja yang duplikasi karena komunikasi hasil pembelajaran dan ide yang ada tidak berlangsung dengan baik. Hal ini dapat diketahui dari terjadinya sejumlah proses fungsi yang bermasalah berulangkali; (3) sulitnya 
memberikan apresiasi kepada staf yang memiliki kontribusi secara langsung atas hasil pembelajaran dan idenya bagi perbaikan organisasi. Hal ini disebabkan karena memang tidak adanya proses yang dapat mengakomodasi bukti kontribusi dan tindak lanjut atas hasil pembelajaran dan ide yang disampaikan.

Dengan kondisi ini organisasi berupaya mengembangkan lingkungan belajar untuk staf yang dapat mengakomodasi ide-ide baru dari staf termasuk hasil pembelajarannya. Pentingnya lingkungan pembelajaran yang kondusif yang dapat memacu munculnya ide-ide baru dari staf memerlukan juga sebuah sarana sistem pembelajaran efektif untuk mengelola ide-ide yang disampaikan oleh staf. Kondisi awal saat dimulainya rencana ini adalah di mana staf yang memiliki ide-ide dan hasil pembelajaran lainnya banyak berada dalam pikiran (tacit knowledge) dan dinyatakan dalam cara yang informal. Cara informal ini bisa dalam bentuk diskusi informal, pesan email, dan catatan-catatan lainnya yang sulit diidentifikasi dan dikelola. Dari kebutuhan ini maka muncul rencana inisiatif yang disebut manajemen ide atau idea management (IM) guna dapat mengidentifikasi nilai strategis yang dapat dinyatakan, memfasilitasi proses-proses pengelolaan ide yang diperlukan hingga kepada rencana pengukuran yang ditargetkan. Selain itu melalui Manajemen Ide ini bisa dimanfaatkan bagi usaha perbaikan organisasi secara terus-menerus serta meningkatkan staff engagement dalam bekerja di organisasi.

Berdasarkan latar belakang kebutuhan di atas, tujuan penulisan ini adalah menyajikan konsep pengembangan model idea management yang disiapkan di World Vision dengan menggunakan landasan teori dari disiplin knowledge management. Konsep ini diharapkan dapat menjadi menjadi referensi kasus praktis dari penerapan disiplin knowledge management dan dapat dijadikan pembanding bagi pengembangan model idea management di organisasi lainnya. Nilai inovasi dari model idea management yang diberikan ini adalah adanya integrasi dari model siklus KM generik dengan siklus khusus proses idea management. Selain itu penerapan konsep obyektif perbaikan operasional QCDSM, Six Hats creative thinking, matrik prioritas, serta beberapa kategori atribut lainnya yang dipergunakan untuk mendefinisikan ide dapat menjadi nilai inovasi tulisan ini.

\section{METODE}

\section{Manajemen Ide}

Idea management (IM) didefinisikan oleh Vandenbosch, et al (2006: p260) sebagai sebuah proses yang dimulai dari mengenali kebutuhan ide-ide yang diperlukan, menangkap dan menghasilkan ide-ide tersebut serta mengevaluasinya sehingga dapat menghasilkan nilai manfaat. Idea management ini sendiri dalam industri sering juga disebut dengan Employee Suggestion System, yaitu sistem yang melibatkan staf mengkontribusikan pengetahuannya bagi ide perbaikan yang bisa dilakukan di organisasinya.

Ide yang ditangkap dapat dibedakan menjadi dua macam dampak kepentingan (importance) bagi organisasi. Yang pertama adalah dampak dari sebuah ide yang bersifat incremental berupa ide yang bertujuan untuk meleakukan perbaikan secara bertahap seperti mengurangi error kerja atau juga yang bersifat leapfrog yaitu berupa ide yang dapat berimpak besar seperti mengubah model bisnis organisasi. Selain itu relevansi ide juga dapat dibagi berdasarkan urgency waktu pelaksanaannya yaitu ide yang perlu segera ditindaklanjuti untuk diterapkan ataupun yang dapat ditindaklanjuti dalam waktu yang lebih panjang lagi. Berdasarkan dari nilai importance dan urgency suatu ide, organisasi dapat memetakan prioritas tindak lanjut suatu ide. 


\section{Persepsi Ide}

Salah satu hal yang penting dalam mengelola sebuah ide adalah bagaimana kita dapat menstrukturkan pengetahuan seseorang untuk dapat dituangkan dalam sebuah dokumen sehingga orang lain dapat memahaminya dengan obyektif. Dalkir (2011) menyatakan bahwa agar sebuah ide dapat berhasil diimplementasikan perlu memastikan terjadinya perubahan dari pemahaman pengetahuan dari si pemilik ide menjadi ide yang dapat dipahami dengan persepsi yang tepat oleh orang lain sehingga siap untuk dikolaborasikan. Untuk itu dalam IM perlu dapat menilai isi ide yang disampaikan. Hal ini sangat penting untuk dapat menjadi acuan bersama bagaimana staf yang memiliki beragam tacit idea dapat menuangkannya secara terstruktur dan komunikatif untuk dinilai oleh orang lain dengan persepsi yang obyektif.

Untuk mengembangkan persepsi ide menjadi lebih obyektif bagi semua staf, maka dalam IM perlu memiliki model obyektif yang standar dan mudah digunakan secara lintas fungsi/departemen. Dalam model IM ini maka ide distrukturkan dalam lima obyektif QCDSM yang terdiri dari: Quality, Cost, Delivery, Safety, dan Morale (Greasley, 2008). Lima obyektif ini dipergunakan dalam model IM ini karena QCDSM sudah menjadi obyektif continuos improvement yang dapat dipergunakan melakukan perbaikan proses operasional dalam suatu manajemen mutu yang diterapkan dalam berbagai bisnis yang berbeda-beda (Black, 2008).

\section{Konversi Ide}

Berdasarkan model knowledge conversion Nonaka dan Takeuchi (1996: 62), IM ini mengalami proses konversi pengetahuan yang meliputi tiga macam (Gambar 1) yaitu: (1) externalization yang merupakan bentuk konversi ide seseorang dari tacit knowledge menjadi explicit knowledge. Mediasi bentuk transfer ini adalah seperti menggunakan formulir manual dan elektronik yang dipergunakan oleh staf menuangkan idenya secara terstruktur; (2) combination yang merupakan bentuk konversi ide seseorang yang sudah didokumentasikan kemudian digabungkan dengan ide lainnya yang sudah ada untuk mendapatkan hubungan yang melengkapi satu sama lainnya. Proses konversi combination ini dilakukan menggunakan aplikasi yang mempermudah membuat dan menemukan koneksi antara satu ide dengan ide lainnya; (3) internalization adalah bentuk transfer ide dari yang sudah dikodifikasikan untuk dipelajari/dikaji yang untuk seterusnya dapat diberikan penilaian (rating), potensi pemanfaatan dan implementasinya, dan komentar yang memperkaya konteks ide. Proses internalization ini difasilitasi menggunakan aplikasi SI yang memampukan user untuk mengakses dan mempelajari ide yang tersimpan.

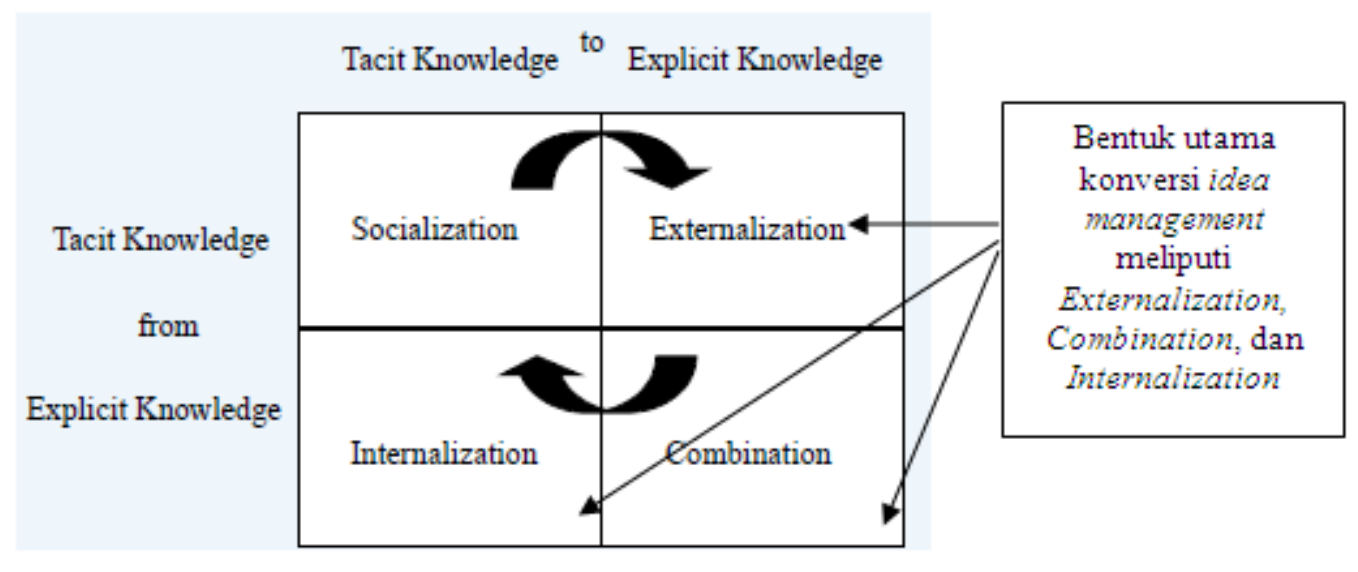

Gambar 1 Knowledge conversion (Nonaka dan Takeuchi, 1996) 


\section{Siklus Manajemen Ide}

Dasar dari siklus IM yang dipergunakan adalah tahap-tahap generik dari suatu model knowledge management yang kemudian dispesifikasikan menjadi model siklus IM. Model dasar siklus IM ini sendiri diadaptasi dari alur proses employee suggestion scheme yang disampaikan oleh Chan (2012) dalam lokakarya internasional yang diadakan oleh Asia Productivity Organization (APO) tahun 2011.

Model siklus generik KM dari Probst (2000) menjadi landasan utama untuk membuat konteks manajemen ide ini secara luas dalam WVIDN. Model siklus ini meliputi: (1) penetapan tujuan dan obyektif IM secara strategis dan operasional; (2) pengidentifikasian (identification) hal-hal yang diperlukan untuk seorang staf dapat menuangkan ide-idenya secara obyektif dan terstruktur; (3) pengakuisisian (acquisition) ide-ide yang muncul untuk dapat ditangkap dan disimpan; (4) pengembangan (development) ide-ide menjadi siap dikaji dan diekskalasi; (5) pendistribusian (distribution) ide-ide kepada stakeholder; (6) pendayagunaan (utilization) ide menjadi manfaat secara operasional; (7) penahanan (retention) sumber (originator) dan hasil ide-ide serta pembelajaran yang disampaikan oleh para staf; (8) pengukuran (measurement) hasil dan dampak IM yang dijalankan.

Sedangkan secara lebih spesifik alur model IM ini mengadaptasi model employee suggestion scheme (ESS) yang disampaikan oleh Teian Consulting dalam lokakarya Asia Productivity Organization (APO) di Manila (Chan, 2012). Bagian utama model ESS ini (Gambar 2) dimulai dari proses staf menyampaikan suggestion-nya, keterlibatan supervisor dalam memberikan kajian, keberadaan komite dalam memberikan penilaian dan publikasi, proses koordinasi dengan fungsi departemen lain yang terlibat, rencana apresiasi dan acknowledgement kepada staf, serta kemungkinan tindak lanjut dalam bentuk implementasi yang layak dikerjakan nanti.

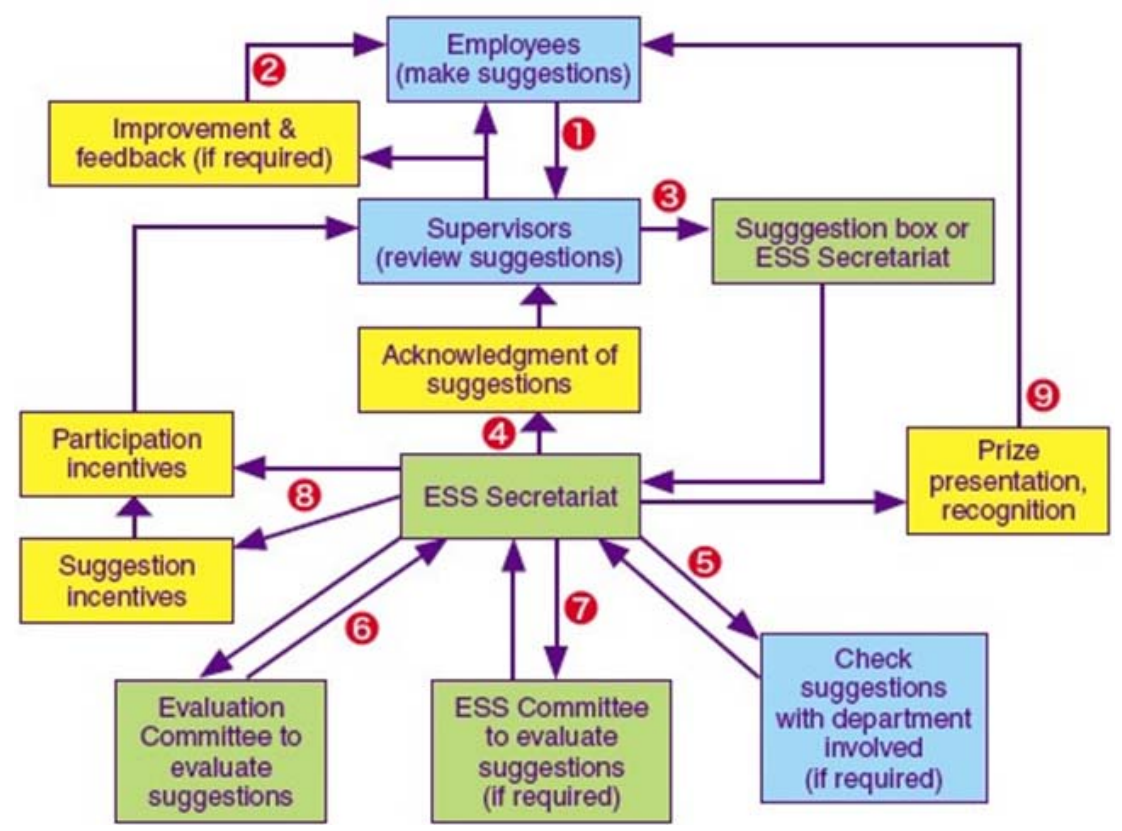

Gambar 2 Tipikal alur proses sebuah employee suggestion system (Chan, 2012)

\section{Creative Thinking untuk Ide}

Dalkir (2011) menyatakan bahwa dalam proses menghasilkan ide dalam membantu menyelesaikan sebuah problem, membangun sebuah produk atas jasa diperlukan kreativitas. Untuk 
menunjang kreativitas dalam menghasilkan ide ini maka digunakan metode Six Hats Creative Thinking yang dibuat oleh Edward de Bono. Puccio dan Cabra (2010) dalam artikelnya menunjukkan bukti bahwa metode ini dapat menghasilkan dampak yang besar dalam proses menghasilkan ide dan meningkatkan kontribusi partisipan dalam menyampaikan pendapatnya.

Metode ini menguraikan ide dalam enam perspektif berpikir yang masing-masing diwakili oleh warna topi. Masing-masing topi itu adalah topi putih untuk menyatakan data/fakta suatu ide, topi merah yang menyatakan emosi atau perasaan, topi kuning yang mewakili rasa antusias dan pemikiran positif, topi hitam yang menunjukkan sis negatif dari ide, topi hijau yang dipakai untuk mencari alternatif atau inovasi dalam sebuah ide, dan topi biru yang akan mengkonsolidasi semua pemikiran secara ringkas dan menunjukkan kemungkinan tindak lanjutnya.

\section{HASIL DAN PEMBAHASAN}

\section{Pembahasan Strategi Pembelajaran WVIDN dan Kondisinya}

Merujuk kepada dokumen rencana strategi WVIDN 2008-2011 (Country Strategy 2008-2011, 2008), terdapat beberapa hal yang menjadi dasar terkait dengan pentingnya pengelolaan ide dan hasil pembelajaran di WVIDN. Beberapa poin penting arahan strategis yang dinyatakan sebagai berikut: (1) WVIDN menyadari bahwa proses pembelajaran perlu terkoordinasi dan terkonsolidasi pada level nasional. Hal ini dilakukan agar skala pemanfaatan pengetahuan dan hasil pembelajaran yang diperoleh dapat diekskalasi menjadi skala nasional. Hasil pembelajaran dan pengetahuan ini diharapkan dapat menjadi bagian proses perencanaan dan pengambilan keputusan baik dari level strategi hingga operasional (Country Strategy 2008-2011, 2008); (2) WVIDN dalam pemilihan strategisnya (strategic choice) mengungkapkan pentingnya mengembangkan pembelajaran yang bersifat lintas fungsi. Organisasi akan mengarahkan bagaimana pembelajaran setiap departemen atau fungsi dapat terhubung satu dengan lainnya untuk meningkatkan kualitas dari integrasi pelayanan (Country Strategy 2008-2011, 2008). Dalam hal ini terlihat bahwa hasil pembelajaran ide-ide yang dimiliki oleh staf perlu dapat saling menunjang lintas fungsi; (3) sebagai pemilihan strategisnya, WVIDN juga mengarahkan strateginya agar mampu mengembangkan budaya organisasi yang mendukung staf untuk secara secara berkala dapat meningkatkan kompetensi dan kemampuannya (Country Strategy 2008-2011, 2008).

Melihat ketiga poin di atas, terlihat bahwa proses pembelajaran menjadi arahan level strategis bagi WVIDN. Namun proses pembelajaran dan idea sharing yang biasa difasilitasi organisasi masih dilakukan secara kovensional yang terfokus kepada bentuk lokakarya, seminar, dan pelatihanpelatihan kelas. Bentuk pembelajaran melalui bentuk pertemuan ini mempunyai batasan pada kapasitas organisasi untuk mampu mengkoordinasi dan menyelenggarakannya. Selain dalam bentuk pelatihan kelas, sumber dan proses pembelajaran untuk mendapatkan ide-ide yang disampaikan staf yang saat ini terjadi adalah berasal dari dokumen-dokumen laporan yang disampaikan dalam laporan operation semi/annual report, baseline report, project design, evaluation report, trip report, dan dokumen informal lainnya. Untuk kondisi ini, proses pembelajaran untuk mengangkat ide-ide dari sumber dokumen-dokumen ini tidak mudah dilakukan dikarenakan cukup sulit bagi staf lintas fungsi lainnya memahami struktur dan relevansi penulisan, mengidentifikasikan inti dari ide yang disampaikan, serta tidak ada proses yang baku untuk memonitor tindak lanjut pemanfaatan hasil pembelajaran yang dapat secara langsung meningkatkan kompetensi staf dan kemampuannya dalam bekerja.

Dalam hal ini, organisasi menyadari bahwa organisasi perlu menyediakan alternatif proses pembelajaran yang dapat dilakukan sendiri secara aktif oleh para staf. Hal ini dilakukan dengan cara 
para staf diberikan kesempatan menyatakan hasil pembelajaran dan ide-idenya yang untuk kemudian dikelola oleh organisasi secara sistematis sehingga organisasi dan staf lainnya juga dapat memanfaatkan hasil pembelajaran dan ide-ide yang disampaikan.

Pengelolaan ide-ide dan hasil pembelajaran ini harus ditujukan untuk dapat menjawab kebutuhan strategis WVIDN. Kebutuhan utama dalam memulai pengembangan sebuah IM ini adalah perlunya model sistem IM yang dapat menstrukturkan ide, mengelolanya secara sistematis, mengekskalasi di level nasional, memperkaya dan menghubungkan ide yang diberikan, dapat memonitor hasil realisasinya, serta dapat mempertahankan ide dan sumber ide bagi para staf.

\section{Konsep Model IM WVIDN}

Berdasarkan kebutuhan strategis dan operasional WVIDN di atas, direncanakan inisiatif strategis yaitu berupa pengorganisasian ide-ide baru dan hasil pembelajarannya yang mampu mengelola ide-ide yang disampaikan oleh staf. Perumusan rencana inisiatif IM ini mempunyai tiga sasaran terkait peningkatan kapasitas organisasi, yaitu: (1) memampukan organisasi melakukan transformasi ide dari tacit knowledge menjadi aset knowledge base organisasi yang dapat secara nyata dikelola dan terukur dampaknya; (2) memampukan staf untuk dapat secara mudah dan terstruktur menyampaikan ide-ide dan hasil pembelajaran mereka bagi proses perbaikan organisasi dengan skala yang lebih luas; (3) memampukan organisasi untuk dapat mengenali partisipasi staf yang memberikan kontribusi ide-idenya dan hasil pembelajarannya sehingga organisasi dapat secara transparan dan efektif memberikan penghargaan yang layak bagi keterlibatan staf.

Selanjutnya sasaran di atas diterjemahkan menjadi rancangan konsep model IM berdasarkan landasan teori yang digunakan. Konsep IM ini secara sistem merupakan satu set proses pengelolaan pengetahuan yang terdiri dari delapan langkah utama berupa: penetapan tujuan IM, mengidentifikasi (identify), mengakuisisi (acquire), mengembangkan (develop), mendistribusikan (distribute), mendayagunakan (utilize), mempertahankan (retain) ide-ide dan hasil pembelajarannya serta mengukur (measure) indikator dampak yang diharapkan. Langkah-langkah generik ini dipetakan dalam prosedur dan fungsi aplikasi yang dirancang untuk mendukung proses yang diharapkan. Knowledge conversion secara paralel juga digunakan sesuai dengan langkah siklus model IM ini sehingga memperjelas tahapan-tahapan perubahan bentuk transfer ide yang terjadi.

Gambar 3 dibawah ini adalah rancangan model pengembangan IM yang mengintegrasikan langkah generik pengelolaan IM beserta alur prosedur, rancangan fungsi utama aplikasi serta knowledge conversion yang terjadi. Rancangan model pengembangan ini memiliki tujuh langkah yang sesuai langkah generik KM dimulai dari penetapan tujuan IM hingga pengukuran indikator dampaknya.

\section{Langkah 1: Penetapan Tujuan Inisiatif IM WVIDN}

Langkah ini merupakan awal dari idea externalization yang dimulai dari penetapan tujuan inisiatif idea management yang dibagi menjadi dua level yaitu: (1) level strategis yang bertujuan mengarahkan IM untuk dapat mendukung pencapaian inisiatif strategis tahunan dan jangka panjang empat tahunan serta KPI organisasi; (2) level operasional yang bertujuan mengarahkan IM dapat mendukung peningkatan kompetensi inti, kinerja proses bisnis inti yang ada, dan inovasi pendukung lainnya yang belum dimiliki/dilakukan organisasi.

Berdasarkan dari tujuan di atas ini, setiap kontribusi ide yang diberikan harus dapat dikaitkan dengan dua level tujuan tersebut. Langkah ini merupakan arahan strategis yang diberikan oleh level manajemen puncak. 


\section{Langkah 2: Idea Identification}

Ini merupakan langkah menerjemahkan ide yang disampaikan staf ke dalam sistem secara sistematis yang harus dapat mudah dimengerti. Ada tiga hal dalam langkah idea identification yang dilakukan sebagai berikut.

Pertama, menetapkan atribut-atribut ide untuk identifikasi ide yang terdiri dari tujuh bagian yaitu; (1) heading idea identification yang merupakan bagian atribut dasar dari identifikasi ide yang terdiri dari idea ID, submission date, idea title, originator, other contributor, expected functional units involved, technology involved, external parties, dan other resources; (2) idea description yang merupakan bagian uraian detail dari ide yang disampaikan oleh staf sepanjang maksimum tiga halaman tulisan yang terdiri dari body of idea, keywords, dan references; (3) QCDSME values identification. Bagian atribut ini dipakai untuk menstrukturkan dan menjelaskan ide yang disampaikan dalam enam obyektif, yaitu: quality (bagaimana ide memberikan/ meningkatkan kualitas layanan), cost (bagaimana ide mempengaruhi biaya layanan), delivery (bagaimana ide mempengaruhi cara Anda memberikan layanan), safety (bagaimana ide menyediakan keamanan layanan), morale (bagaimana ide memiliki efek pada moral layanan), dan environment (bagaimana ide mempengaruhi lingkungan layanan); (4) organization contribution and alignment category status and explanation identification yang terdiri dari dua bagian. Pertama adalah idea contribution to organization objectives. Bagian ini mengidentifikasikan apakah ide yang disampaikan berkontribusi bagi level strategis atau operasional WVIDN. Strategic Level Objective choices terdiri dari pilihan list of current annual strategic initiative, list of Four-yearly strategic initiative, dan list of Coporate KPI. Operational Level Objective choices terdiri dari pilihan: list competency contribution, list of core process contribution, dan other innovation contribution.

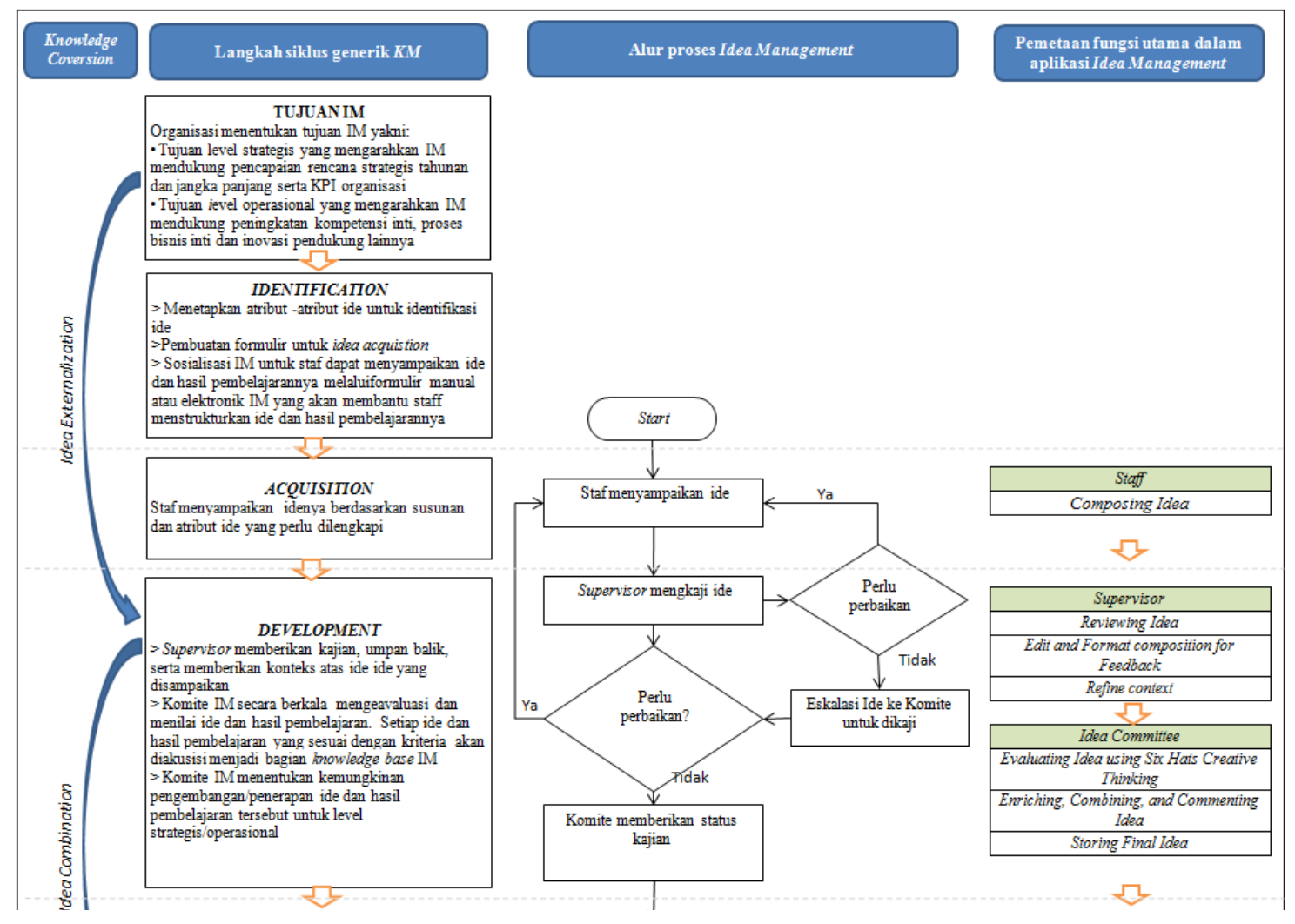




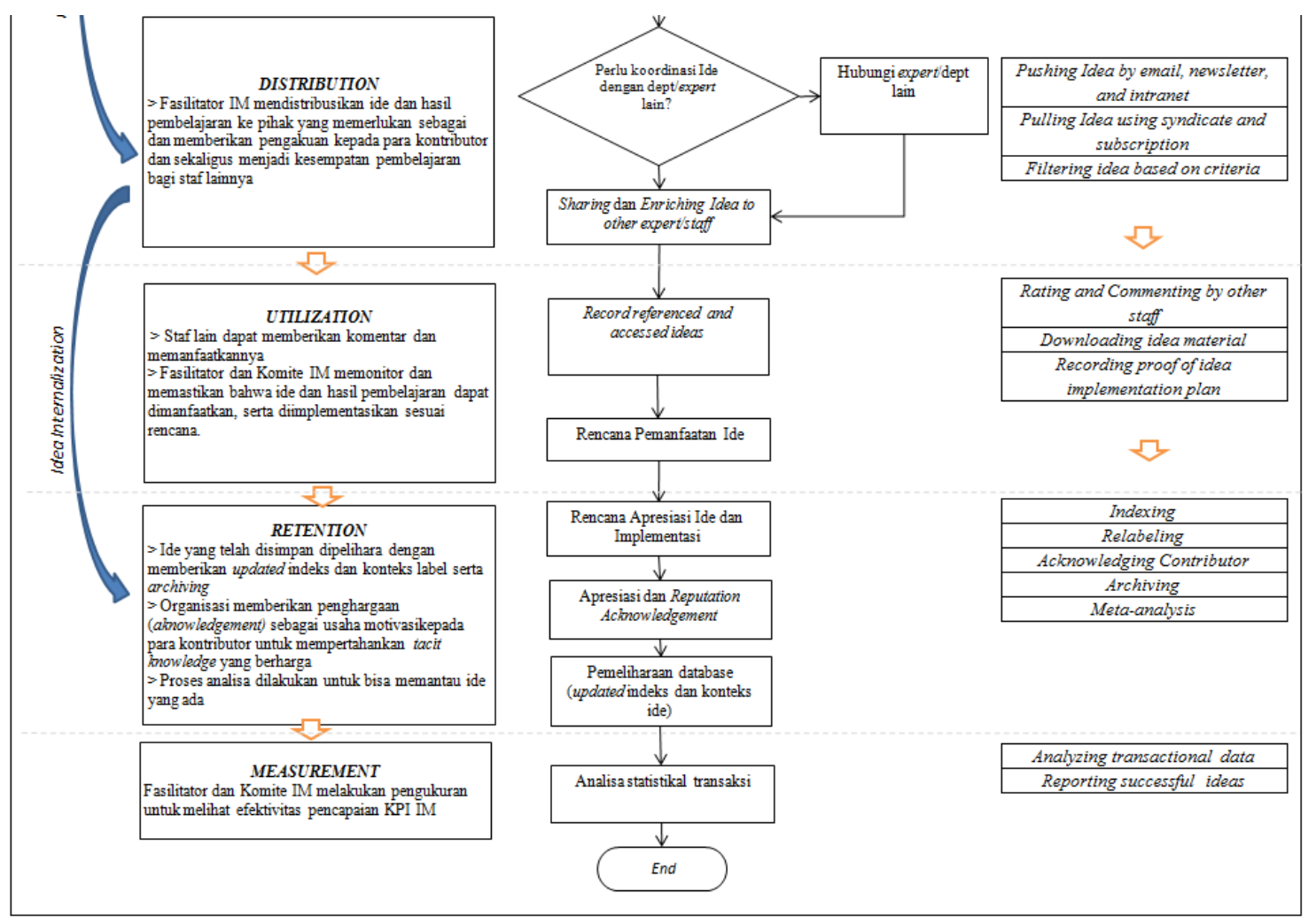

Gambar 3 Konsep model pengembangan IM

Kedua adalah idea alignment with organization principles and capacity. Bagian ini merupakan atribut untuk melihat keselarasan ide dengan prinsip dan kapasitas organisasi dengan memberikan status Yes/No dan penjelasannya. Atribut ini terdiri dari: (a) principle level choices: tackles the root causes of poverty, multiple ministry focus, empowerment,dan ministry-driven; (b) Christian, child-focused, community based; (c) apakah WVIDN saat ini memiliki kapasitas untuk mencapai hasil yang diharapkan? (HR, pengetahuan, sistem, dan struktur, dll); (e) jika tidak, dapat kita membeli atau berpartner untuk meningkatkan kapasitas? (5) priority matrix and the risk of not taking the idea identification. Bagian ini merupakan atribut untuk mengenali skala prioritas tindak lanjut yang diperlukan serta resiko yang mungkin terjadi bila ide yang disampaikan tidak direalisasikan. Tingkat kepentingan: tinggi (memiliki dampak kritis sekarang dan masa depan periode), medium (memiliki dampak yang penting untuk periode saat ini atau masa depan), rendah (memiliki dampak bagi periode berikutnya). Tingkat urgensi: tinggi (harus dilaksanakan dalam enam bulan ke depan), sedang (harus diimplementasikan pada tahun kinerja saat ini), rendah (dapat diterapkan pada periode berikutnya). Deskripsi dampak negatif tidak mengambil inisiatif tersebut; (6) Six Hats Creative Thinking identification. Bagian atribut ini menjabarkan proses berpikir kreatif secara lateral sehingga dapat mengakomodasi diskusi atau umpan balik yang disampaikan oleh staf terkait, atasan, komite ide, maupun staf lainnya. Six Hats Creative Thinking dalam tulisan ini tidak dibahas secara detail. Untuk memahami lebih dalam dapat melihatnya di referensi online http://www.debonothinkingsystems.com/tools/6hats.htm; (7) follow up status identifaction and Log of comments. Bagian ini merupakan atribut untuk menjelaskan status tindak lanjut ide oleh komite ide serta komentar lainnya.

Langkah kedua dalam idea identification adalah mendesain formulir idea identification sesuai dengan atribut-atribut ide dalam langkah 1a di atas. Desain idea identification form dapat dilihat pada Gambar 4. 
Langkah ketiga adalah sosialisasi IM untuk staf dapat menyampaikan ide dan hasil pembelajarannya melalui formulir identifikasi ide baik secara manual atau elektronik IM yang akan membantu staf menstrukturkan ide dan hasil pembelajarannya.

\begin{tabular}{|c|c|c|c|}
\hline \multicolumn{4}{|c|}{ Heading Idea Identification } \\
\hline Idea Id & (auto number) & \multirow[t]{2}{*}{ Topic } & \multirow{2}{*}{ (free text) } \\
\hline Submission date & (date format) & & \\
\hline Originator & (drop down employee name) & Other Contributors & (drop down employee name) \\
\hline $\begin{array}{l}\text { Expected Functional Units } \\
\text { Involved }\end{array}$ & (drop down division name) & External Parties & (free text) \\
\hline $\begin{array}{l}\text { Estimated Technology } \\
\text { Involved }\end{array}$ & $\begin{array}{l}\text { (drop down application } \\
\text { technology platform) }\end{array}$ & Other Resources & (free text) \\
\hline \multicolumn{4}{|c|}{ Idea Description } \\
\hline Body of Idea Composition & \multicolumn{3}{|l|}{ (free text) } \\
\hline Keywords: & \multicolumn{3}{|l|}{ (free text) } \\
\hline References: & \multicolumn{3}{|l|}{ (free text) } \\
\hline \multicolumn{4}{|c|}{ Idea V a lu e } \\
\hline $\begin{array}{l}\text { Quality } \\
\text { (How your initiative } \\
\text { gives/improves the } \\
\text { QUALITY of your sevice) }\end{array}$ & \multicolumn{3}{|c|}{ (free text) } \\
\hline $\begin{array}{l}\text { Cost } \\
\text { (How your initiative affects } \\
\text { the COST of your service) }\end{array}$ & \multicolumn{2}{|c|}{ (free text) } & (currency) \\
\hline $\begin{array}{l}\text { Delivery } \\
\text { (How your initiative affects } \\
\text { the way you DELIVER your } \\
\text { service) }\end{array}$ & \multicolumn{3}{|c|}{ (free text) } \\
\hline \begin{tabular}{|l} 
Safety \\
(How your initiative provide \\
the SAFETY of your service)
\end{tabular} & \multicolumn{3}{|c|}{ (free text) } \\
\hline $\begin{array}{l}\text { Morale } \\
\text { (How your initiative has an } \\
\text { effect on the MORALE of } \\
\text { your service) }\end{array}$ & \multicolumn{3}{|c|}{ (free text) } \\
\hline $\begin{array}{l}\text { Environment } \\
\text { (How your initiative affects } \\
\text { the ENVIRONMENT of your } \\
\text { service) }\end{array}$ & \multicolumn{3}{|c|}{ (free text) } \\
\hline
\end{tabular}

\begin{tabular}{|c|c|c|}
\hline \multicolumn{3}{|c|}{ Idea Organization Alignment Justification } \\
\hline Alignment Category & IES/NO & Justificetion \\
\hline \multicolumn{3}{|c|}{ 1. Aligament with Organization Objectires } \\
\hline $\begin{array}{l}\text { Current Annual Strategic } \\
\text { Initiative }\end{array}$ & $\begin{array}{l}\text { (drop down list of WVIDN } \\
\text { Strategic Initiatives) }\end{array}$ & (free text) \\
\hline Four-Yearly Strategic Initiative & $\begin{array}{l}\text { (drop down list of WVIDN } \\
\text { Strategic Initiatives) }\end{array}$ & (free text) \\
\hline Organitation KPI Contribation & $\begin{array}{l}\text { (drop down list of WVIDN } \\
K P(s)\end{array}$ & (free text) \\
\hline Competesey & $\begin{array}{l}\text { (drop down list of WVIDN } \\
\text { competency Dictionary) }\end{array}$ & (free text) \\
\hline Process & $\begin{array}{l}\text { (drop down list of WVIDN } \\
\text { Standard Operating } \\
\text { Procedures) }\end{array}$ & (free text) \\
\hline Oether Innoratice & (drop down YESWNO) & (free text) \\
\hline \multicolumn{3}{|c|}{ 2. Alignment with Organization Principles and Capacity } \\
\hline $\begin{array}{l}\text { WVIDN Principle Level Choices: } \\
\text {-Tackles the root causes of } \\
\text { poverty } \\
\text {-Multiple ministry focus } \\
\text {-Empowerment } \\
\text {-Ministry-Driven }\end{array}$ & (drop down YES/NO) & (free text) \\
\hline $\begin{array}{l}\text { Christian, Child-Focused, } \\
\text { Community Based }\end{array}$ & (drop down YES/NO) & (free text) \\
\hline $\begin{array}{l}\text { Does WVIDN currently have } \\
\text { capacity to achieve expected } \\
\text { results? (HR, knowledge, } \\
\text { systems, and structures, etc) }\end{array}$ & (drop down YES/NO) & (free text) \\
\hline
\end{tabular}




\begin{tabular}{|c|c|c|c|}
\hline $\begin{array}{l}\text { If WVIDN does not currently } \\
\text { have capacity to achieve expected } \\
\text { results can we purchase or } \\
\text { partner to increase capacity? }\end{array}$ & (drop down YES/NO) & \multicolumn{2}{|c|}{ (free text) } \\
\hline \multicolumn{4}{|c|}{ Idea Priority Matrix } \\
\hline Level & Low & Medium & High \\
\hline Importance & (radio button) & (radio button) & (radio button) \\
\hline Urgency & (radio button) & (radio button) & (radio button) \\
\hline $\begin{array}{l}\text { Describe Negative Impacts of } \\
\text { Not Taking the Initiative }\end{array}$ & \multicolumn{3}{|c|}{ (free text) } \\
\hline \multicolumn{4}{|c|}{ Idea Creative Thinking - Six Hats } \\
\hline White Hat & \multicolumn{3}{|l|}{ (free text) } \\
\hline Red Hat & \multicolumn{3}{|l|}{ (free text) } \\
\hline Black Hat & \multicolumn{3}{|l|}{ (free text) } \\
\hline Yellow Hat & \multicolumn{3}{|l|}{ (free text) } \\
\hline Green Hat & \multicolumn{3}{|l|}{ (free text) } \\
\hline Blue Hat & \multicolumn{3}{|l|}{ (free text) } \\
\hline \multicolumn{4}{|c|}{ Idea Follow Up } \\
\hline Follow Up & (drop down YES/NO status) & \multirow{2}{*}{\multicolumn{2}{|c|}{ (free text) }} \\
\hline Comment & (free text) & & \\
\hline
\end{tabular}

Gambar 4 Idea identification form

\section{Langkah 3: Idea Acquisition}

Dalam langkah ini staf menyampaikan idenya secara eletronik atau manual terlebih dahulu. Tahap ini merupakan langkah utama dalam idea externalization yang berhubungan dengan fungsi utama aplikasi yaitu fungsi composing idea. Dalam menyampaikan ide, staf menstrukturkan idenya sesuai atribut identifikasi ide no 1 hingga 7. Ketujuh bagian ini yang akan dikaji dan dikolaborasikan bersama atasan (supervisor) dan Komite IM mulai langkah ke 4 Idea Development.

\section{Langkah 4: Idea Development}

Langkah 4 ini merupakan realisasi idea combination di mana ide staf dikombinasikan dengan atasannya serta Komite IM. Dalam hal ini ide yang telah dibuat staf selanjutnya disampaikan ke atasannya untuk dikaji, dikoreksi, diberikan umpan balik serta diperkaya konteks idenya. Fungsi utama aplikasi untuk bagian ini yang dapat dilakukan atasan adalah terkait dengan reviewing, editing, refining idea yang dilakukan oleh atasan staf.

Bila ide telah diverifikasi oleh atasannya, selanjutnya ke Komite IM untuk mengevaluasi dan menilai ide yang disampaikan sehingga dapat divalidasi ke dalam knowledge base. Komite IM ini akan menentukan kemungkinan pengembangan pemanfaatan ide dan prioritasnya. Rancangan fungsi utama aplikasi yang dipergunakan oleh Komite IM dalam langkah ini adalah fungsi evaluasi menggunakan metode creative thinking six hats, fungsi untuk memperkaya (enriching) ide, mengkombinasikan dengan ide lainnya, memberikan keterangan komentar, serta memvalidasi ide ke dalam basis data.

\section{Langkah 5: Idea Distribution}

Langkah 5 ini merupakan idea internalization di mana ide yang sudah disimpan dalam knowledge base didistribusikan ke staf lainnya untuk dapat diakses. Bila diperlukan koordinasi dan konsultasi dengan para expert atau unit lainnya fasilitator IM akan mendistribusikannya secara khusus sehingga dapat memperkaya (enriching) ide sebagai bentuk idea combination.

Distribusi ide ini juga merupakan cara untuk memberikan pengakuan (acknowledgement) kepada para kontributor dalam bentuk publikasi yang dilakukan dengan menggunakan dua fungsi utama aplikasi untuk distribusi ide ini yaitu: push (menggunakan email, newsletter, dan portal intranet) 
dan pull (menggunakan sindikasi informasi dan user registration). Selain itu fungsi utama yang penting juga adalah filtering yang membantu pencarian ide berdasarkan atribut identifikasi ide yang dibuat dalam langkah 1 di atas.

\section{Langkah 6: Idea Utilization}

Langkah ini merupakan bagian idea internalization di mana ide yang telah dikembangkan tersebut kini siap diinternalisasi menjadi bagian inisiatif organisasi. Fasilitator dan Komite IM memonitor dan memastikan bahwa akses dan penggunaan ide dan hasil pembelajarannya dapat terekam. Dalam hal ini staf lainnya yang mengakses, mengunduh bahan materi, memberikan komentar dan penilaian (rating) dijadikan sebagai bagian bahan indikator utilisasi ide. Selain itu status utilisasi ide ini dapat diberikan dengan cara Komite IM menyiapkan rencana implementasi/pemanfaatannya yang disampaikan sebagai bukti pemanfaatannya yang terdapat dalam atribut tindak lanjut ide ini. Langkah ini akan menunjukkan indikator besar kecilnya utilisasi masing-masing ide dan seberapa banyak ide yang berhasil terealisasi. Fungsi utama aplikasi yang disiapkan adalah rating and commenting by other staff, downloading idea material, dan recording proof of idea implementation plan.

\section{Langkah 7: Idea Retention}

Yang diperhatikan dalam langkah 7 ini adalah mempertahankan ide dan idea originator. Ide yang telah disimpan akan dipelihara dengan memperbaharui indeks dan konteks label serta archiving yang diperlukan. Hal ini penting untuk membuat ide yang telah disampaikan dapat terus sesuai dengan konteks kebutuhan staf. Fungsi utama yang diperlukan adalah fungsi indexing, relabeling, acknowledging contributor, serta archiving. Selain itu dalam tahap ini perlu ada proses analisa untuk bisa memantau ide yang ada secara lebih luas (meta analysis) sehingga dapat terlihat hubungan antara satu ide dengan ide lainnya menggunakan indeks, tags, dan konteks yang telah dilengkapi. Sedangkan untuk mempertahankan staf yang memberikan kontibusi idenya, maka organisasi memberikan penghargaan (aknowledgement) sebagai usaha motivasi kepada para kontributor untuk mempertahankan tacit knowledge yang berharga. Penghargaan ini perlu menjadi satu kesatuan dalam model aplikasi IM yang dikembangkan.

\section{Langkah 8: Idea Measurement}

Fasilitator dan Komite IM mengukur efektivitas pencapaian indikator kinerja IM baik yang terekam dalam aplikasi sistem maupun dengan pengukuran survei lainnya. Tabel 1 berisi sepuluh indikator yang digunakan untuk mengukur dampak IM dalam dua level.

Tabel 1 Indikator Pengukuran Idea Management

\begin{tabular}{|c|c|}
\hline Tingkatan Manajemen & Indikator Kinerja \\
\hline $\begin{array}{l}\text { Level Strategis - Indikator ide dan hasil } \\
\text { pembelajarannya ini dipergunakan sebagai } \\
\text { penunjang secara langsung dasar perencanaan } \\
\text { inisiatif strategis WVIDN tahunan. }\end{array}$ & $\begin{array}{l}\text { (1). inisiatif strategis yang berasal dari IM } \\
\text { (2). ide yang mendukung pencapaian KPI organisasi } \\
\text { (3). yang berhasil direplikasi berskala nasional }\end{array}$ \\
\hline $\begin{array}{l}\text { Level Operasional - Indikator di level ini } \\
\text { dipergunakan untuk mengukur frekuensi ide } \\
\text { terkait dengan perbaikan proses kerja, } \\
\text { komptensi kerja, inovasi, ide yang berhasil } \\
\text { diimplementasi, serta transaksional akses } \\
\text { lainnya }\end{array}$ & $\begin{array}{l}\text { (4). staf yang berkontibusi menyampaikan ide dalam IM } \\
\text { (5). ide yang terkait untuk meningkatkan kompetensi } \\
\text { pekerjaan } \\
\text { (6). ide bagi perbaikan proses berjalan } \\
\text { (7). ide untuk menghasilkan inovasi } \\
\text { (8). ide yang ditindaklanjuti untuk diimplementasikan } \\
\text { (9). user akses perbulannya } \\
\text { (10). komentar/umpan balik yang diberikan untuk ide }\end{array}$ \\
\hline
\end{tabular}


Langkah 8 ini merupakan siklus terakhir dalam satu proses pengelolaan ide yang dipergunakan untuk menunjukkan indikator kinerja IM yang diharapkan.

\section{High-Level Fungsi Utama Aplikasi IM}

Dari delapan langkah siklus KM yang diuraikan di atas terdapat, 20 fungsi utama yang teridentifikasi harus dipetakan dalam rencana aplikasi IM. Fungsi utama tersebut disusun berdasarkan langkah siklus KM di atas dimulai dari tahap akuisisi hingga pengukuran ide seperti dalam

Gambar 5 dibawah ini.

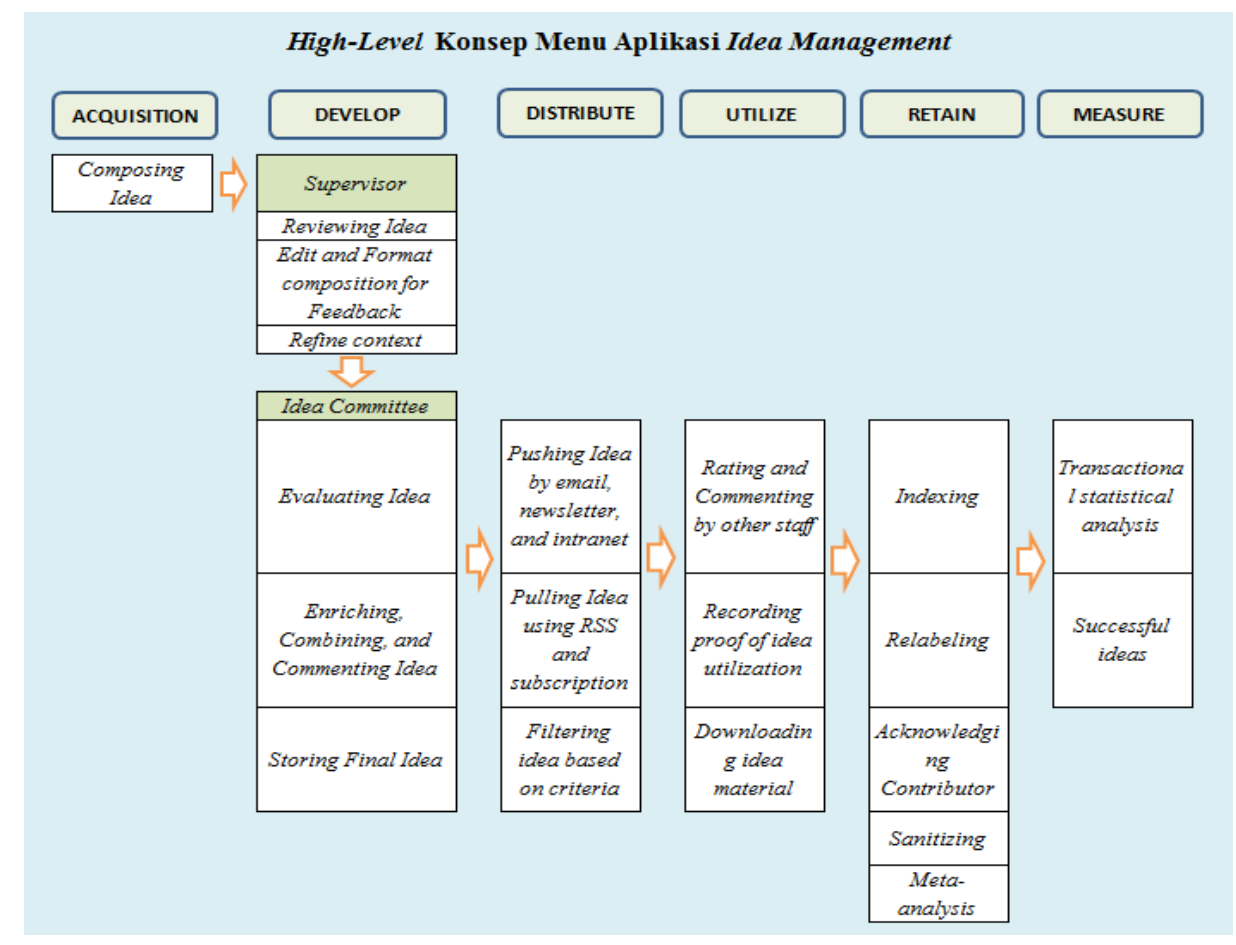

Gambar 5 High level fungsi utama aplikasi idea management

Fungsi composing idea adalah fungsi saat langkah siklus idea acquisition yang diperlukan bagi staf untuk menyusun idenya dalam formulir identifikasi ide. Dalam hal ini aplikasi membantu staf menuliskan apa saja bagian yang perlu diisi berikut dengan pilihan-pilihan yang tersedia. Bagian berikutnya di siklus development, terdapat fungsi bagi supervisor untuk mengkaji (review), mengedit dan memberikan umpan balik serta menambah/memperjelas konteks ide sehingga menjadi lebih relevan bagi pengguna lainnya. Fungsi menjadi bagian yang sangat penting di mana staf dan atasan dapat berkolaborasi mengembangkan idenya. Sedangkan untuk fasilitator dan Komite IM terdapat fungsi untuk mengevaluasi ide sekaligus untuk memperkayanya dengan mengkombinasikan sebuah ide yang dikaji dengan ide yang sudah ada lainnya ataupun dari pemikiran para anggota Komite IM. Setelah divalidasi, maka ide tersebut disimpan dalam basis data.

Fungsi selanjutnya dalam tahap distribusi ide terdapat fungsi publikasi dengan cara push (menggunakan email, newsletter, dan intranet) dan pull (menggunakan sindikasi dan user subscription) untuk memastikan ide yang dipublikasikan diterima sesuai tujuan pengguna yang diharapkan. Fungsi ini menjadi pilihan bagi user untuk menerima publikasi ide tersebut secara massal atau sesuai dengan permintaan. Bagian atribut dari ide yang telah diidentifikasi perlu dapat dipilah oleh pengguna dengan menggunakan fungsi filter berdasarkan kriteria yang dicari. 
Selanjutnya fungsi dalam tahap utilisasi adalah fungsi untuk mengukur penggunaan ide dengan menggunakan fungsi rating dan commenting dan downloading yang bisa dilakukan oleh pengguna lainnya. Dalam tahap utilisasi ini juga perlu fungsi yang dapat dipakai untuk melengkapi bukti dari rencana pemakaian ide yang akan disiapkan oleh Komite IM.

Pada bagian siklus ide selanjutnya yaitu idea retention, terdapat fungsi untuk memelihara ide yang ada agar tetap kontekstual dengan memberikan indeks, pembaharuan label/tag, archiving/sanitizing data ide yang tidak digunakan lagi, dan fungsi meta analysis untuk melihat kumpulan basis data ide. Sedangkan sebagai bagian upaya memberikan pengakuan kepada para kontributor ide, maka dalam IM ini perlu ada fungsi utama untuk acknowledging contributor dengan menampilkan nama serta reputasi staf yang dapat mudah dikenali. Bagian fungsi terakhir dalam tahap pengukuran adalah fungsi untuk menghitung transaksi-transaksi yang terjadi untuk bisa menghasilkan indikator kinerja yang diinginkan serta dapat melaporkan ide yang dikategorikan berhasil.

Melalui uraian delapan langkah dalam IM yang diintegrasikan dengan desain atribut identifikasi ide, alur proses untuk prosedur IM, rancangan fungsi utama aplikasi, serta idea conversion, hal ini dapat menjadi model bagi pengembangan IM di WVIDN. Model pengembangan yang sama ini juga diyakini dapat menjadi referensi model pengembangan IM di organisasi lainnya.

\section{PENUTUP}

Melalui konsep model pengembangan yang dibahas di atas, kebutuhan IM sebagai cara untuk merealisasikan kemampuan pembelajaran di WVIDN dapat terakomodasi. Integrasi konsep knowledge conversion dan langkah generik KM telah memberikan model dasar untuk melihat tahapan pengembangan ide yang terjadi di WVIDN. Prosedur pengelolaan ide juga telah disusun untuk mengatur alur proses ide dari tahapan identifikasi hingga pengukuran ide. Konsep QCDSM telah dipakai untuk menstrukturkan nilai sebuah ide sehingga besarnya kontribusi dapat diperkirakan. Matriks prioritas yang terdiri dari nilai importance dan urgency dapat memberikan kesepakatan kemungkinan implementasi ide. Penggunaan six hats creative thinking yang merupakan cara berpikir lateral dapat dipergunakan untuk menunjang aspek diskusi kreatif dalam mempersepsikan sebuah ide. Penyertaan secara khusus kategori organization alignment WVIDN dalam model IM ini dapat menjadi bagian esensial untuk melihat apakah ide tersebut sejalan dengan kriteria pilihan dan prinsip organisasi. Bagian terakhir, dalam model pengembangan IM ini juga disertakan sejumlah sepuluh indikator esensial yang bisa diukur dari sistem IM secara langsung ataupun tidak langsung

\section{DAFTAR PUSTAKA}

Black, John R. (2008). Lean production: implementing a world class system. New York: Industrial Press.

Chan, Kelvin. (2012). Productivity Methodologies, Tools, and Technique: Harnessing Collective Wisdom Through Employee Suggestion Schemes. Diakses 15 August 2012 dari http://www.apo-tokyo.org/productivity/pmtt_004.htm.

Dalkir, Kimiz. (2011). Knowledge Management Theory and Practice (second ed.). Boston, MA: MIT Press.

Deichmann, D. (2012). Idea management: perspectives from leadership, learning, and network theory. 
ERIM Ph.D. Series Research in Management, 255. Rotterdam: Erasmus University Rotterdam.

Greasley, Andrew. (2008). Operations Management. London: SAGE Publications.

Nonaka, I., Takeuchi, H. (1995). The Knowledge-Creating Company: How Japanese Companies Create The Dynamics of Innovation. New York: Oxford University Press.

Probst, G., Raub, S., Romhardt, K. (2000). Managing Knowledge: Building Blocks for Success. New Jersey: John Willey.

Puccio, Gerrard J., Cabra, John F., (2010). Organizational Creativity: A System Approach. Dalam Kaufman, James C., Sternberg, Robert J. (2006). The Cambridge Handbook of Creativity. Cambridge: Cambridge University Press 